\title{
Growth of wild and domesticated Atlantic cod Gadus morhua reared under semi-commercial conditions
}

\author{
Håkon Otterå ${ }^{1, *}$, Mikko Heino ${ }^{1,2}$, Anne Grete Eide Sørvik ${ }^{1}$, Terje Svåsand ${ }^{1}$, \\ Ørjan Karlsen ${ }^{3}$, Anders Thorsen ${ }^{1}$, Kevin A. Glover ${ }^{1,2}$ \\ ${ }^{1}$ Institute of Marine Research, 5817 Bergen, Norway \\ ${ }^{2}$ Department of Biological Sciences, University of Bergen, 5020 Bergen, Norway \\ ${ }^{3}$ Institute of Marine Research, Austevoll Research Station, 5392 Storebø, Norway
}

\begin{abstract}
Genetic interactions between farmed escapees and wild fish represent a challenge to environmentally sustainable aquaculture. Breeding programs for Atlantic cod Gadus morhua have been initiated; however, the genetic response to selection, and therefore the degree of domestication, has not been evaluated. We compared growth of 2 wild and 2 partly domesticated strains that had been under selection for 2 generations. Offspring of 54 synchronously produced families were reared in 2 common-garden experiments, each consisting of Phase I: parallel rearing in mesocosms and tanks 0-8 mo post-hatch, and Phase II: rearing in tanks or sea-cages 8-18 and 8-34 mo post-hatch, respectively. One of the domesticated strains displayed significantly higher growth compared to the wild Northeast Arctic cod population (48-67\% higher weight), while the other domesticated strain had a similar growth rate to the Northeast Arctic cod population. The wild population from southern Norway displayed a significantly higher growth rate compared to the wild Northeast Arctic cod population. These results represent the first experimental estimation of domestication-driven changes in farmed cod, and demonstrate that the first breeding programs for this species have been partially successful, resulting in improved growth rates of cod in 2 generations.
\end{abstract}

KEY WORDS: Aquaculture $\cdot$ Microsatellite $\cdot$ Heritability $\cdot$ Escapees

\section{INTRODUCTION}

Domestication alters the genetic structure of cultured animals in ways that make them better adapted to a life in captivity (e.g. Duarte et al. 2007), but can, on the other hand, make them less adapted to a life in the wild (e.g. Hutchings \& Fraser 2008, Wringe et al. 2015). The domestication process may be subtle, going on for decades without any deliberate selection, or much more rapid, through carefully designed breeding programs with strong directional selection for commercially important traits as has been the case for Atlantic salmon Salmo salar (Gjedrem 2000, 2010).

\footnotetext{
*Corresponding author: haakon.otteraa@hi.no
}

Either way, the genetic structure of the captive strain will be altered through selection of those individuals that are most productive in captivity to propagate the next generation. Domestication will often be a prerequisite for commercially viable fish-farming, and a number of species of fish are currently being domesticated for food production (Teletchea \& Fontaine 2014).

Atlantic cod Gadus morhua is an economically important gadoid fish inhabiting the North Atlantic. In Norway, a combination of dwindling coastal cod stocks and the highly successful Atlantic salmon aquaculture triggered interest in commercial Atlantic cod

() The authors 2018. Open Access under Creative Commons by Attribution Licence. Use, distribution and reproduction are unrestricted. Authors and original publication must be credited. 
production during the 1980s. Although Atlantic cod aquaculture did not display the same rapid expansion in production as experienced by the Atlantic salmon farming industry, by the turn of the century, commercial Atlantic cod aquaculture was being conducted in Norway, Scotland, Faroe Islands, Iceland and Canada, in addition to pilot-scale efforts elsewhere (Svåsand et al. 2004). In Norway, which was and remains as the largest commercial producer of farmed Atlantic cod, production peaked at $21000 \mathrm{t}$ in 2010 (Directorate of Fisheries, Bergen, Norway, www.fiskeridir.no), although it dwindled thereafter and is currently at a very low level (5 $\mathrm{t}$ in $2015, \sim 0 \mathrm{t}$ in 2016).

Many of the early scientific efforts to initiate commercial Atlantic cod aquaculture concentrated on technological improvements in rearing systems, especially to increase larval survival and increase production of robust juveniles suitable for on-growing to market size in marine cages (e.g. Brown et al. 2003). In addition, other challenges such as high liver growth and early maturation, which retard somatic growth and thus profitability, have been the subject of significant scientific efforts (e.g. Karlsen et al. 2006). An important step in the direction of commercializing Atlantic cod aquaculture in Norway was taken in 2001 when a government-financed Atlantic cod breeding program was started in the hope that it could repeat the success of the Norwegian salmon breeding programs initiated in the early 1970s (Gjedrem et al. 1991, Gjedrem 2010). In addition, several private companies involved in Atlantic cod farming started their own breeding programs in Norway and in other countries during the same period. The overall goal for these breeding programs was to develop domesticated strains of Atlantic cod that displayed high productivity and good health in the aquaculture environment, and specifically, increased growth rates.

Heritability $\left(h^{2}\right)$ for Atlantic cod body weight has been examined in several studies. In Norwegian studies, heritability for this trait was estimated from a low of 0.16 to a high of 0.52 (Gjerde et al. 2004, Kolstad et al. 2006a, Bangera et al. 2011, 2015). In Icelandic aquaculture production, $h^{2}$ was estimated at 0.31 (Kristjánsson \& Arnason 2016), while in eastern North America, heritability estimates for body weight have been reported at 0.15 for juveniles and 0.27 for larger fish (Tosh et al. 2010). Furthermore, heritability for body weight at harvest was estimated at 0.35 (Garber et al. 2010). These estimates of heritability for body weight in Atlantic cod overlap with estimates in Atlantic salmon (Gjedrem 2000, 2010), where several-fold increases in growth have been achieved as a result of domestication (Glover et al. 2017).

Domesticated fish are a cause of concern if they escape and interbreed with wild conspecifics (Bekkevold et al. 2006, Glover et al. 2017). In contrast to Atlantic salmon, farmed cod have 2 possibilities to escape into the wild. The first is by spawning within net pens, and the subsequent release of fertilized eggs into the surrounding water masses (Jørstad et al. 2008). The second is by physical escape from net pens, a significant challenge in current cod culture systems (Uglem et al. 2008, Jensen et al. 2010, Glover et al. 2011, Serra-Llinares et al. 2013, Zimmermann et al. 2013, Jørstad et al. 2014).

Increased growth rate is the primary goal of most, if not all, fish breeding programs. For Atlantic salmon that has currently undergone $\geq 12$ generations of selection, this represents the trait that displays the largest genetic difference between domesticated and wild conspecifics (Glover et al. 2017). Therefore, growth rate serves as a good indicator of divergence between domesticated and wild stocks, including cod where high heritability for this trait has been reported (see above). However, to date, no study has investigated the growth differences between domesticated cod strains and wild populations. To provide the first data on this, we compared the growth of 2 domesticated strains and 2 wild populations that were reared under semi-commercial conditions.

\section{MATERIALS AND METHODS}

\section{Overall experimental design}

To compare growth between partially domesticated and wild cod strains, we implemented a 'common-garden' design involving 2 parallel experiments (Expts A and B). Both involved synchronous family production, mixing of offspring into a common-garden rearing environment, PIT tagging and identification of fish to family using DNA analysis, and measuring growth at 2 stages of production (Fig. 1). We chose a common-garden experimental design as it has been extensively implemented to elucidate genetic differences between domesticated and wild salmon (Glover et al. 2017), and because it reduces environmental noise and the need for multiple tanks for each family/strain.

We established 2 parallel experiments: Expt A, with a full dam $\times$ sire factorial design, and Expt $B$, with a reduced design with common dam $\times$ sire crosses to eliminate the (non-genetic) maternal effect. 


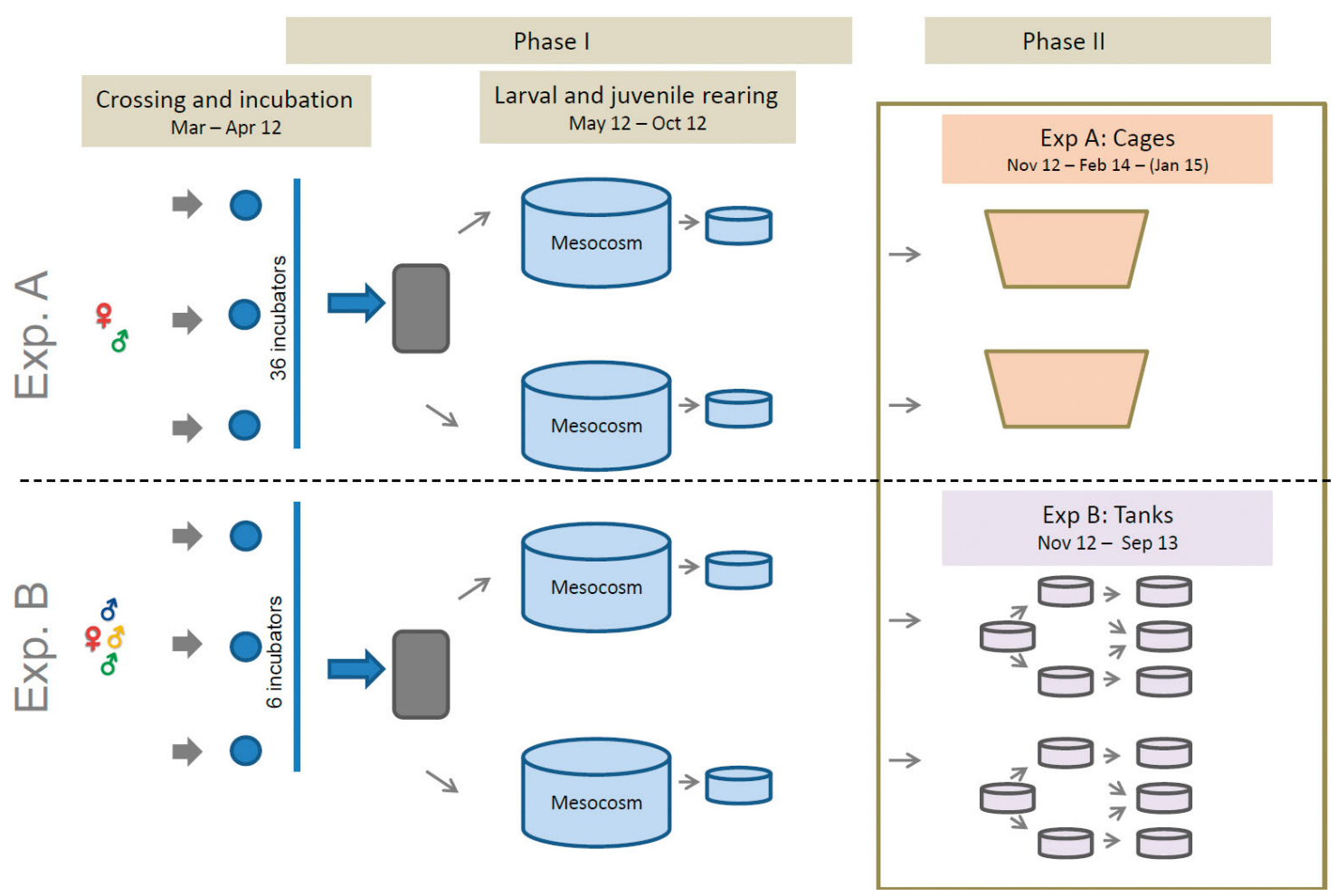

Fig. 1. Overview of the experiments. Egg batches from available female cod were split in 2-4 portions, each fertilized with males of different origin, and incubated. The difference in number of incubators between Expt A and B is mainly due to different breeding design between the experiments. In Expt A, each incubator contained 1 cross, while in Expt B, each incubator contained 3 crosses (common female $\times 3$ males; see 'Materials and methods' for further details). At the time of hatching, the larvae from the incubators were mixed together in equal proportions (Expts A and B separately) and then divided into 2 replicate mesocosms for larval and juvenile rearing. After harvest from the mesocosms and a period of further growth in holding tanks, approximately 1000 individuals from each of the 4 tanks (mesocosms) were used in a growth experiment, either in cages (Expt A) or tanks (Expt B). The tanks were split on 2 occasions due to the growing biomass

These were established using different sets of families. Based on our experience, maternal effects can be of significance in cod, particularly due to issues with egg-bound females (see below). The use of 2 independent experiments therefore increased the robustness of the study. The rearing conditions for Expts A and B were identical for Phase I, which included rearing fish in mesocosms from $0-2$ mo posthatch, then in replicated tanks from 2-8 mo posthatch. At this stage, a random sample of the survivors was DNA parentage tested to identify them to family, measured and individually tagged. Thereafter, the fish entered Phase II, which included rearing them in semi-commercial conditions either in sea cages under ambient temperature (Expt A, 8-34 mo posthatch) or in tanks on land with stable temperature (Expt B, 8-18 mo post-hatch). The use of a semi-natural environment in Phase I (mesocosms, with natural feed and low larval density) was a practical approach that had proved to be an efficient and reliable method for producing high-quality juveniles to supply the farming industry for many years (Svåsand et al. 2004). The growth experiment took place at IMR Austevoll, while broodstock, egg, larval and juvenile rearing took place at IMR Parisvatnet. Both facilities are located close to Bergen, western Norway.

\section{Broodstock}

The following broodstock from 4 Norwegian strains and populations were used in the experiments: (1) wild-caught Northeast Arctic (NEA) cod, (2) wild-caught coastal cod (CC), (3) domesticated Atlantic cod from the National breeding program (D1) and (4) domesticated Atlantic cod from the Marine Breed breeding program (D2).

The NEA cod represents one of the most important commercial fish stocks in northern Europe. It is highly migratory with spawning migration from the main feeding area in the Barents Sea to the spawning grounds along the Norwegian coast (Bergstad et al. 1987). The NEA broodstock used in the present study was captured by bottom trawl from the RV 'G.O. 
Sars' east of the island of Hopen in the Barents Sea in November 2009. Approximately 360 specimens (average weight $2 \mathrm{~kg}$ ) were transported to the Institute of Marine Research (IMR) research facility at Parisvatnet $\left(60^{\circ} 37^{\prime} \mathrm{N}, 4^{\circ} 47^{\prime} \mathrm{E}\right)$, where they were used as broodstock for various experiments. When the present experiment was initiated, 109 fish were available as broodstock.

$\mathrm{CC}$ along the Norwegian coast are much more stationary than the NEA cod, and are divided into many small subpopulations which can be distinguished genetically (Knutsen et al. 2003). For this experiment, we used wild CC collected by trammel or fyke nets in the coastal area close to our research facility Parisvatnet, on the west coast of Norway, where the experiment was conducted. At the time of the experiment, approximately 130 fish (average weight $3.5 \mathrm{~kg}$ ) were available from this group.

The Norwegian national breeding program for Atlantic cod (which supplied D1 cod) is described by Bangera et al. (2011). In December 2010, 86 individuals from D1 were acquired from Nofima, Tromsø $\left(69^{\circ} 52^{\prime} \mathrm{N}, 18^{\circ} 55^{\prime} \mathrm{E}\right)$, and transported to Parisvatnet. These represented 17 full-sibling families of the F2 generation domesticated Atlantic cod hatched in 2009, originating from wild-caught NEA cod. They weighed approximately $0.6 \mathrm{~kg}$ at arrival to the Parisvatnet facility.

The fourth broodstock group (D2) was purchased from the commercial Norwegian breeding company Marine Breed, a subsidiary of Akvaforsk Genetics Center. Fish $(n=100)$, with an average weight of approximately $2 \mathrm{~kg}$, were transported from a broodstock test station (Sagafjord, Stord, 59 $45^{\prime}$ N, $5^{\circ} 29^{\prime}$ E) to Parisvatnet in July 2010. These were F2 generation domesticated Atlantic cod, produced in 2008, originating from an unquantified mixture of CC and NEA cod captured in 2002.

Both the National cod breeding program (D1) and Marine Breed (D2) have used a combination of family- and individual-based selection, with growth as the primary breeding goal. All domesticated and wild broodstock were held in sea cages and fed formulated feed (Amber Neptun /Vitalis Repro, depending on season, www.skretting.com). The temperature varied between 3 and $17^{\circ} \mathrm{C}$ during the year.

\section{Family production and egg incubation}

Available broodstock were stripped for eggs and milt on 19 and 20 March 2012 for Expt A, and 21 March for Expt B. Fish were taken from their respec- tive cages with a landing net and placed on a table where eggs or milt were collected. Fish were calm and easy to handle. It was therefore not necessary to anesthetize the fish before gametes were removed from mature fish by gently stroking. Cultured Atlantic cod are often egg-bound (van der Meeren \& Ivannikov 2006, Árnason \& Björnsson 2012), which means that they do not spawn and release the eggs. Eggbound females also represented a challenge in the experiments reported here. This, and to some extent the limited number of males that gave milt on these dates, resulted in an experimental design less balanced than initially planned.

Within $2 \mathrm{~h}$ post-stripping, gametes were taken to the nearby hatchery for fertilization. For Expt A, each of the egg batches was divided equally into 2-4 subbatches (depending on the egg amount) and fertilized with $5 \mathrm{ml}$ milt from 1 male per sub-batch. The milt was gently mixed with the eggs, and seawater was thereafter added to activate the eggs (provide mobility). After $1 \mathrm{~min}$, jars with fertilized eggs were transferred to 1801 incubators supplied with ca. 11 $\min ^{-1}$ seawater and in addition air-bubbling to prevent the eggs from getting sucked into the outlet sieve. For Expt B, we divided eggs from each female into 3 sub-batches, fertilized these with milt from 3 separate males, and thereafter incubated them together in the same type of incubator as for Expt A. The number of families that hatched in sufficient number for larval rearing was 36 in Expt A, and 18 in Expt B (Table 1). Temperature during incubation was approximately $6^{\circ} \mathrm{C}$.

\section{Phase I - Larval and juvenile rearing 0-8 mo post-hatch}

In both experiments, eggs hatched approximately $2 \mathrm{wk}$ after fertilization. These were transferred to the larval incubators within 1-2 d post-hatch, and on 4 April 2012, the number of larvae in each of the incubators was estimated. The water in each incubator was agitated to ensure homogenous larval distribution, while 3 volumetric samples were taken and counted to determine the number of larvae $\mathrm{l}^{-1}$ water. Based on this estimated density, a volume corresponding to 5556 larvae was taken from each of the 36 incubators in Expt A and mixed together ( 200 000 larvae in total). This mixture was thereafter divided into 2 equal portions, and 100000 larvae were placed into each of the 2 mesocosms for rearing up to 2 mo old. The same procedure was used for Expt B, where the mixture of larvae from 6 incubators (containing 3 
Table 1. Overview of number of Atlantic cod crosses (dam $\times$ sire) that were produced to hatch and survived in sufficient numbers to be used in growth calculations $(\mathrm{N}>9)$. Numbers in parentheses indicate number of individuals per cross. The dams are listed as individuals, such that e.g. NEA-1 eggs were split in 2 and fertilized with one D1 and one D2 male. Experimental groups are NEA: wild Northeast Arctic cod, CC: wildcaught coastal cod, D1: domesticated cod from the Norwegian national breeding program, D2: domesticated cod from a commercial breeder

\begin{tabular}{|c|c|c|c|c|c|}
\hline \multirow{2}{*}{$\begin{array}{l}\text { Expt A } \\
\text { Dam }\end{array}$} & & Siro & & & \multirow{2}{*}{ Sum } \\
\hline & NEA & $\mathrm{CC}$ & D1 & D2 & \\
\hline NEA-1 & - & - & $1(14)$ & $1(15)$ & 2 \\
\hline NEA-2 & $3(38,12,25)$ & - & - & - & 3 \\
\hline NEA-3 & $1(71)$ & 1 (135) & $1(119)$ & 1 (235) & 4 \\
\hline NEA-4 & $2(27,95)$ & $1(32)$ & - & - & 3 \\
\hline NEA-5 & $1(44)$ & - & $1(61)$ & - & 2 \\
\hline D1-1 & - & - & - & $2(84,35)$ & 2 \\
\hline D1-2 & $1(56)$ & - & - & $1(148)$ & 2 \\
\hline D1-3 & $1(17)$ & $1(25)$ & - & $1(60)$ & 3 \\
\hline D1-4 & 1 (180) & $1(22)$ & $1(25)$ & $1(32)$ & 4 \\
\hline D1-5 & - & - & $1(25)$ & - & 1 \\
\hline D2-1 & - & - & - & $\begin{array}{c}1(57) \\
\text { TOTAL }\end{array}$ & $\begin{array}{c}1 \\
27(1689)\end{array}$ \\
\hline \multirow[t]{2}{*}{$\begin{array}{l}\text { Expt B } \\
\text { Dam }\end{array}$} & \multicolumn{4}{|c|}{ Sire } & \multirow{2}{*}{ Sum } \\
\hline & NEA & \multicolumn{2}{|c|}{ D1 } & D2 & \\
\hline NEA-1 & $1(213)$ & \multicolumn{2}{|c|}{-} & $1(66)$ & 2 \\
\hline D1-1 & $1(283)$ & \multicolumn{2}{|c|}{$1(36)$} & $1(516)$ & 3 \\
\hline D1-2 & $1(38)$ & \multicolumn{2}{|c|}{1 (39) } & $1(117)$ & 3 \\
\hline D1-3 & $1(126)$ & \multicolumn{2}{|c|}{$1(13)$} & $1(47)$ & 3 \\
\hline \multirow[t]{2}{*}{ D1-4 } & $1(100)$ & \multirow{2}{*}{\multicolumn{2}{|c|}{-}} & $1(81)$ & 2 \\
\hline & & & & TOTAL & 13 (1675) \\
\hline
\end{tabular}

families each, as described above) was released into 2 identical mesocosms to those used for Expt A. In Expt $B$, the number of larvae sampled from each incubator was higher ( 33333) in order to achieve the same larval density as in Expt A.

The 4 mesocosms ( 2 for Expt $\mathrm{A}$ and 2 for Expt B) consisted of $7 \times 7 \mathrm{~m}$ wide, $3.5 \mathrm{~m}$ deep, $\sim 175 \mathrm{~m}^{3}$ volume plastic bags suspended in a steel-supported frame floating in Parisvatnet, a large (270000 $\mathrm{m}^{3}$ volume) enclosed natural seawater pond (Blom et al.1991). Water and filtrated zooplankton from the pond were added to ensure water exchange and a supplement of natural prey in addition to the natural live feed production in the mesocosms. As the larvae grew, their natural diet was gradually supplemented with formulated feed (Gemma Micro followed by Gemma Wean and Gemma Diamond, www.skretting.com). On 29-30 May 2012, approximately 2 mo post-hatch, juvenile fish were collected from the 4 mesocosms using a net and transferred to 4 identical tanks (diameter $3 \mathrm{~m}$, volume $7 \mathrm{~m}^{3}$ ). At this stage, $\sim 3000-$ 5000 juveniles were harvested from each of the 4 mesocosms (equating to an average survival of $\sim 4 \%$ ).

Upon entering tanks at 2 mo post-hatch, juveniles were fed a commercially formulated feed for marine fish (Gemma Diamond, Amber Neptun, www. skretting.com) with an excess daily ration. On 4 November 2012, a random sub-set of the fish from each of the 4 tanks was sampled, marking the termination of Phase I of the study. This included weight measurements, taking a DNA sample and PIT tagging for later identification of individuals. During this procedure, fish were anesthetized according to the following procedure: approximately 10 fish were netted each time and transferred into a small tank containing aerated seawater and with $20 \mathrm{mg} \mathrm{l}^{-1}$ tricaine methanesulfonate (MS-222: Finquel). Upon sedation, they were transferred to another tank with clean seawater and rapidly treated one by one as described above, before being transferred to a tank with running seawater. All sampling and fish-handling was conducted by personnel trained according to the Norwegian legislation for animal experimentation. The number of fish that were sampled, assigned to family and entered into Phase II of the study was 886 and 912 for the 2 replicates in Expt A, and 984 and 964 for the 2 replicates in Expt B.

Temperature during larval and juvenile rearing increased from approximately $5.5^{\circ} \mathrm{C}$ in April to a maximum of approximately $17^{\circ} \mathrm{C}$ in August and then decreased down to $12^{\circ} \mathrm{C}$ in October. Mortality between transfer of the juveniles from the mesocosms at $2 \mathrm{mo}$, and when the fish were measured and PIT tagged at the end of Phase I of the experiment (8 mo post-hatch) was low but not accounted for.

\section{Phase II - Growth to adulthood 8+ mo post-hatch}

In both experiments, juveniles were sampled from their respective tanks and transferred either to seacages (Expt A) or land-based tanks (Expt B) (Table 1, Fig. 1). The methods for this phase of the experiment are divided into Expt A and Expt B for clarity.

\section{Expt A}

Phase II of Expt A involved rearing fish from 8-34 mo post-hatch in 2 replicate sea-cages under ambient temperature and light conditions. Each cage was $5 \times 5 \mathrm{~m}$ wide and $8 \mathrm{~m}$ deep. Temperature during the year varied from approximately $3^{\circ} \mathrm{C}$ in February 


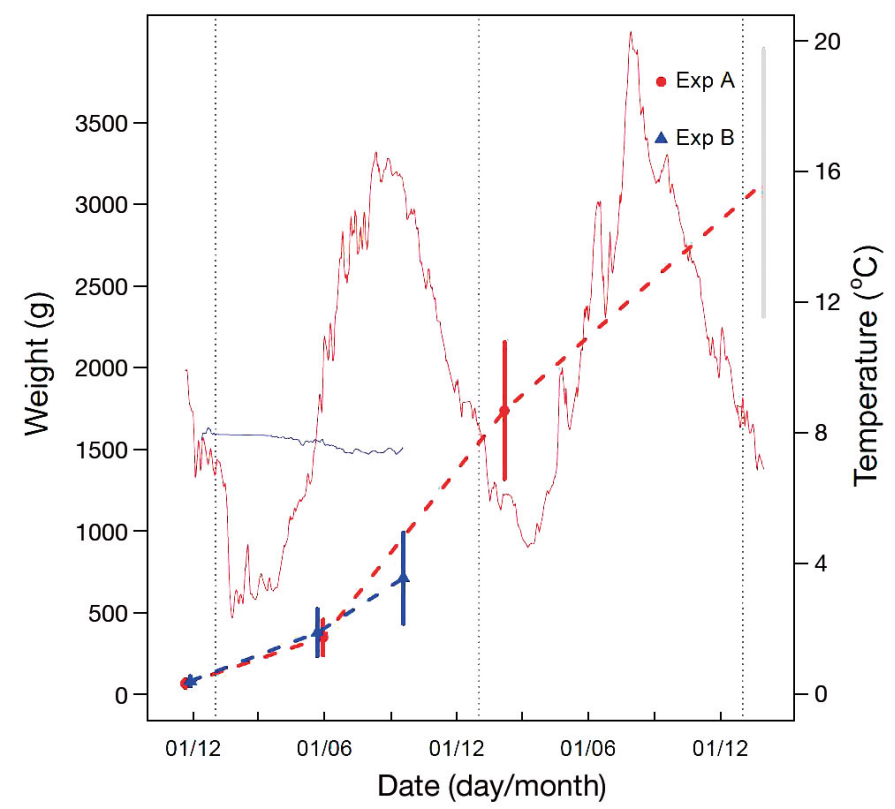

Fig. 2. Overall cod weight (left axis) and water temperature (right axis, solid lines) in Expt A (red) and Expt B (blue). Weight is given as mean \pm SD for all crosses pooled. Due to a mortality incidence during summer 2014, the last datapoint for Expt A represents only approximately $45 \%$ of the individuals present in the previous measurements (SD is shown in grey for this point). Dates are from Nov 2012 to Jan 2015; dotted vertical lines show each 1 Jan

-April up to a maximum of approximately $16^{\circ} \mathrm{C}$ in July-August (Fig. 2). Salinity varied between 29 and 32 ppt. During summer 2014, temperatures at $5 \mathrm{~m}$ depth reached $20^{\circ} \mathrm{C}$, which is unusual for this locality (Fig. 2). Fish were fed a commercial dry feed (Amber Neptun, www.skretting.com), and the pellet size was adjusted during the experiment according to fish size. Fish were fed in excess using automatic feeders during daylight hours, and supplemented with hand feeding once daily.

The next growth measurement was taken in May 2013. Fish were anesthetized (as described above) and their PIT number, length and weight were recorded. In addition, fish were vaccinated against the common bacterial disease vibriosis $(0.05 \mathrm{ml}$ Alpha Marine micro 3, Pharmaq).

The fish were also sampled in February 2014. By this time, it was possible to establish gender and maturation status by gonad biopsy. By measuring the average diameter of the most advanced oocytes (the leading cohort, LC), the onset of spawning in cod can be predicted (Kjesbu 1994, Kjesbu et al. 2010). Fish were first anesthetized, then an ovarian sample $(\sim 0.5 \mathrm{ml})$ was removed by a specially designed plastic tube (Pipelle de Cornier $®$ ) inserted through the genital pore. These samples were stored for at least $2 \mathrm{wk}$ in
$3.6 \%$ buffered formaldehyde before the oocytes were photographed and subsequently size measured by automatic particle analysis (Thorsen \& Kjesbu 2001).

The final measurement, which marked termination of Expt A, was taken at the end of January 2015. At this stage, fish were killed by an overdose of anesthetic prior to any measurements being taken. Thereafter, their PIT number, length and weight were registered. In addition, fish were gutted, and gonad, liver and gutted weight were recorded.

Mortality between the first sample of phase II and the measurement taken in February 2014 was low $(\sim 10 \%)$, and approximately half of the recorded mortality occurred during sampling or a few days after. Unfortunately, the exceptionally warm summer of 2014 resulted in high mortalities during August and September, partly due to a gill parasite (Gyrodactilus sp.). Mortality in this phase was approximately $55 \%$. Consequently, growth comparisons among the families and groups were based upon measurements taken in February 2014 (22 mo post hatch) in order to avoid any potential bias caused by this temperatureinduced mortality. However, gonad and liver weights were only available at slaughter, so these measures are based on the reduced dataset at termination.

\section{Expt B}

Phase II of Expt B involved rearing fish from 8-18 mo post-hatch in 2 replicate $3 \mathrm{~m}$ diameter, green fiberglass tanks with a water volume of $7 \mathrm{~m}^{3}$. Ocean water was pumped from $165 \mathrm{~m}$ deep, and filtrated through a sand filter. Temperature was stable at $8^{\circ} \mathrm{C}$ (range $7.5-8.5^{\circ} \mathrm{C}$, Fig. 2), and salinity at $\sim 34 \mathrm{ppt}_{\text {, }}$ throughout Phase II. Tanks were located outdoors under ambient light conditions but with a tarpaulin hood on top that reduced the light by $\sim 70 \%$. Fish were fed with identical pellets to Expt A. Expt B was terminated in September 2013, and only included growth measurements. Mortality during Phase II of Expt B was low $(\sim 13 \%)$, and partly connected to sampling and handling. Mortality was therefore not included as a parameter in the statistical analysis.

\section{Parental testing}

Microsatellite DNA analysis was used to assign the offspring back to their family of origin for both experiments. DNA was extracted in 96-well plates using Qiagen DNeasy®96 Blood \& Tissue Kits. Each DNA plate contained 2 blanks to ensure a unique identifi- 
cation of the plate. Five microsatellite loci were amplified in 1 multiplex PCR (Gmo8, Gmo19, Gmo35, Gmo37 and Tch11). PCR products were analyzed on an ABI 3730 Genetic Analyzer and sized by GeneScan $^{\text {TM }} 500$ LIZ® Size Standard. Genotypes were identified using GeneMapper V4.0., with manual control of scored alleles, and assigned to family by the use of FAP Family Assignment Program v3.6 (Taggart 2007). These loci have been used in previous studies in this laboratory (Glover et al. 2010, 2011).

\section{Statistical analysis}

Differences in weight, length and condition factor between the families were tested at the end of Phases I and II for both experiments. Only families with at least 10 individuals were included in the analyses. All analyses were carried out on a logarithmic scale, such that the strain effects could be expressed as multiplicative effects. Condition factor was defined as the residuals from weight-length regressions (log-log scale) fitted to all data from the respective sampling. In addition, hepatosomatic index (HSI: liver weight relative to the gutted weight), gonadosomatic index (GSI: gonad weight relative to the gutted weight; Expt A only), specific growth rate $\left(\log \left(\right.\right.$ weight $_{\text {end phase II }} /$ weight $\left._{\text {end phase I }}\right) /$ number of days $)$ and oocyte size (Expt A only) were tested at the end of the experiment. To account for the positive allometry in liver and gonad weights, HSI and GSI were analyzed with models of the form

$\log ($ organ weight $) \sim c_{0}+\ldots+\alpha \log ($ gutted weight)

which corresponds to estimating the relationship organ weight $\sim e^{c_{0}+\ldots} \times$ (gutted weight $)^{\alpha}$, where $c_{0}$ is the intercept and $\alpha$ is the allometric exponent; $\alpha>1$ corresponds to positive allometry. Size dependence of growth was accounted for by including log(start weight) as an explanatory variable. All response variables were assumed to follow a normal distribution after log-transformation.

To account for strain effects, we used mixed linear models with individuals as random effects and strains as fixed effects. The random effects in Expt A were individual sire (25 levels), dam (12 levels) and 'group' (the tank number, 2 levels) as a nuisance variable. Sires were nested within dams, as each sire was used only once. Group was the tank number (2 levels) in Phase I analyses. The fixed effects were the type of sire (strain, 4 levels, with NEA as the reference level) and dam (3 levels, with NEA as the reference level). Models for HSI and GSI also included $\log$ (gutted weight) as a regression variable. When found to be significant, sex (females as the reference level) was also included. The models were thus of the following type:

$$
\begin{aligned}
\log (Y) & \sim C_{0}+C_{1, \text { type of sire }} \\
& +C_{2, \text { type of dam }}+\ldots+r_{\text {sire }}+r_{\text {dam }}+r_{\text {group }}
\end{aligned}
$$

with

$$
\begin{aligned}
r_{\text {sire }} & \sim N\left(0, \sigma_{\text {sire }}^{2}\right), r_{\text {dam }} \sim N\left(0, \sigma_{\text {dam }}^{2}\right) \\
& \text { and } r_{\text {group }} \sim N\left(0, \sigma_{\text {group }}^{2}\right)
\end{aligned}
$$

where $Y$ is the response variable, $c_{0}$ is the intercept, $C_{\mathrm{X}}$ are constants associated with the fixed effects, and $r_{\mathrm{x}}$ are variances of the normally distributed random effects.

The random effects in Expt B were individual sire (13 levels) and 'group,' the latter being a nuisance variable. Group was the tank number (2 levels) in Phase I analyses and tank history (8 levels, see Fig. 1) in Phase II analyses. The fixed effects were the type of sire (strain, 3 levels, with NEA as the reference level) and dam (5 individuals, with the single NEA dam as the reference level). The models were thus of the following type:

$\log (Y) \sim C_{0}+C_{1, \text { type of sire }}+C_{2, \mathrm{dam}}+C_{3, \mathrm{sex}}+r_{\text {sire }}+r_{\text {group }}$ with

$$
r_{\text {sire }} \sim N\left(0, \sigma_{\text {sire }}^{2}\right) \text { and } r_{\text {group }} \sim N\left(0, \sigma_{\text {group }}^{2}\right)
$$

We chose to treat dam as a fixed effect in Expt B because there were only 5 individual dams, and only one of them was NEA, offering a natural designation of a reference level. Significance of terms was assessed through likelihood ratio tests.

Only individuals present in the experiment at termination were included in the analysis. Individuals that could not be genotyped or with missing tag number records were also excluded. All statistical analyses were carried out with the R package 'lme4' (Bates et al. 2014).

\section{RESULTS}

\section{Growth differences between experiments}

In the first sample, which marked the end of Phase I and start of Phase II of the study, fish from both experiments were on average of similar size. At this stage, they were just above 1 yr of age, and averaged 349 and $378 \mathrm{~g}$ in Expts A and B, respectively (Fig. 2). However, during the summer months of 2013, fish reared in the sea cages increased their growth rate compared to the fish held in tanks on land. This may have been due to higher temperatures in the cages at this stage (Fig. 2). 
Table 2. Results of the statistical analyses with mixed models in Expt A. For fixed effects, 'effect' indicates the significance of individual factor levels: + stands for significant $(\mathrm{p}<0.05)$ positive difference relative to the wild Northeast Arctic cod (NEA, for dam and sire group) or females (for sex); -: significant negative difference; $(+)$ : marginally significant $(0.05 \leq p<0.10)$ positive difference; and 0 : no significant difference. The order of dam groups is 'D1, D2' and sire groups is 'CC, D1, D2' (see Table 1 for descriptions of groups). For random effects, 'effect' is the corresponding standard deviation; residual standard deviation is shown for reference. Growth is measured as specific growth rate, with $\log$ (start weight) as an additional explanatory variable to account for growth declining with initial size ( $p<0.0001$ )

\begin{tabular}{|c|c|c|c|c|c|c|c|c|c|c|c|c|}
\hline \multicolumn{3}{|c|}{ End of phase I / start of phase II } & \multicolumn{2}{|c|}{ Weight } & \multicolumn{2}{|c|}{ Length } & \multicolumn{2}{|c|}{ Condition } & & & & \\
\hline & Term & $\mathrm{df}$ & $\mathrm{p}$ & Effect & $\mathrm{p}$ & Effect & $\mathrm{p}$ & Effect & & & & \\
\hline \multirow{3}{*}{$\begin{array}{l}\text { Fixed } \\
\text { effects }\end{array}$} & Sex & 1 & 0.0601 & $(+)$ & 0.1191 & 0 & 0.4048 & 0 & & & & \\
\hline & Dam group & 2 & 0.4279 & 00 & 0.3193 & 00 & 0.0919 & $0(+)$ & & & & \\
\hline & Sire group & 3 & 0.0001 & $+0+$ & $<0.0001$ & $+0+$ & $<0.0001$ & $+0+$ & & & & \\
\hline \multirow{3}{*}{$\begin{array}{c}\text { Random } \\
\text { effects }\end{array}$} & Dam & $\geq 1$ & $<0.0001$ & 0.192 & $<0.0001$ & 0.050 & $<0.0001$ & 0.026 & & & & \\
\hline & Sire & $\geq 1$ & $<0.0001$ & 0.089 & $<0.0001$ & 0.032 & $<0.0001$ & 0.033 & & & & \\
\hline & Tank & $\geq 1$ & $<0.0001$ & 0.074 & $<0.0001$ & 0.018 & 0.0040 & 0.010 & & & & \\
\hline \multicolumn{2}{|l|}{ Residual } & $\leq 1668$ & & 0.289 & & 0.089 & & 0.083 & & & & \\
\hline \multicolumn{3}{|c|}{ End of phase II (Feb 2014) } & \multicolumn{2}{|c|}{ Weight } & \multicolumn{2}{|c|}{ Length } & \multicolumn{2}{|c|}{ Condition } & \multicolumn{2}{|c|}{ Growth } & \multicolumn{2}{|c|}{ Oocyte diameter } \\
\hline & Term & df & $\mathrm{p}$ & Effect & $\mathrm{p}$ & Effect & $\mathrm{p}$ & Effect & $\mathrm{p}$ & Effect & $\mathrm{p}$ & Effect \\
\hline \multirow{3}{*}{$\begin{array}{l}\text { Fixed } \\
\text { effects }\end{array}$} & Sex & 1 & $<0.0001$ & - & 0.0003 & - & $<0.0001$ & - & $<0.0001$ & - & & \\
\hline & Dam group & 2 & 0.8215 & 00 & 0.6726 & 00 & 0.8792 & 00 & 0.2181 & 00 & 0.8363 & 00 \\
\hline & Sire group & 3 & 0.0001 & $+0+$ & 0.0201 & $00+$ & $<0.0001$ & $+0+$ & 0.1260 & $(+)(+)+$ & 0.0388 & $(+) 0+$ \\
\hline \multirow{3}{*}{$\begin{array}{c}\text { Random } \\
\text { effects }\end{array}$} & Dam & $\geq 1$ & 0.7460 & 0.074 & 1 & 0.019 & 0.1479 & 0.029 & $<0.0001$ & 0.019 & 0.1084 & 0.040 \\
\hline & Sire & $\geq 1$ & $<0.0001$ & 0.089 & $<0.0001$ & 0.033 & 0.0004 & 0.030 & $<0.0001$ & 0.019 & $<0.0001$ & 0.044 \\
\hline & Tank & $\geq 1$ & $<0.0001$ & 0.028 & $<0.0001$ & 0.010 & 1 & $<0.001$ & 1 & $<0.001$ & $<0.0001$ & 0.020 \\
\hline Residual & & $\leq 1677$ & & 0.186 & & 0.064 & & 0.103 & & 0.050 & & 0.081 \\
\hline
\end{tabular}

\section{Expt A (growth in mesocosms, tanks, then sea cages, 0-34 mo posthatch)}

Dam group (D1 or D2 compared to NEA) showed large variation for most of the parameters measured both at the end of Phases I and II. The only significant difference was higher condition factor at the end of Phase I for the D2 group (Table 2, Fig. 3). On the other hand, sire group (CC, D1 or D2) showed significant differences compared to the NEA reference group in most of the measurements, at the end of both phases (Table 2, Fig. 4).

Both the CC and particularly D2 sire-groups displayed a significantly higher weight at the end of Phase I compared to NEA, while D1 had a modeled sire effect similar to NEA. The same weight patterns were also evident at the end of Phase II; however, the relative differences of $\mathrm{CC}$ and $\mathrm{D} 2$, relative to NEA, were reduced compared to the first weight measurement (Fig. 4). Accounting for the initial weight at the start of Phase II, modeled growth during this phase was similar among the sire groups, although D2 still displayed significantly higher growth than NEA, but D1 and particularly CC displayed only marginally significant differences to NEA (Table 2, Fig. 4). Average weight per sire group at the end of the experiment (February 2014) was $1934 \mathrm{~g}$ for D2 compared to

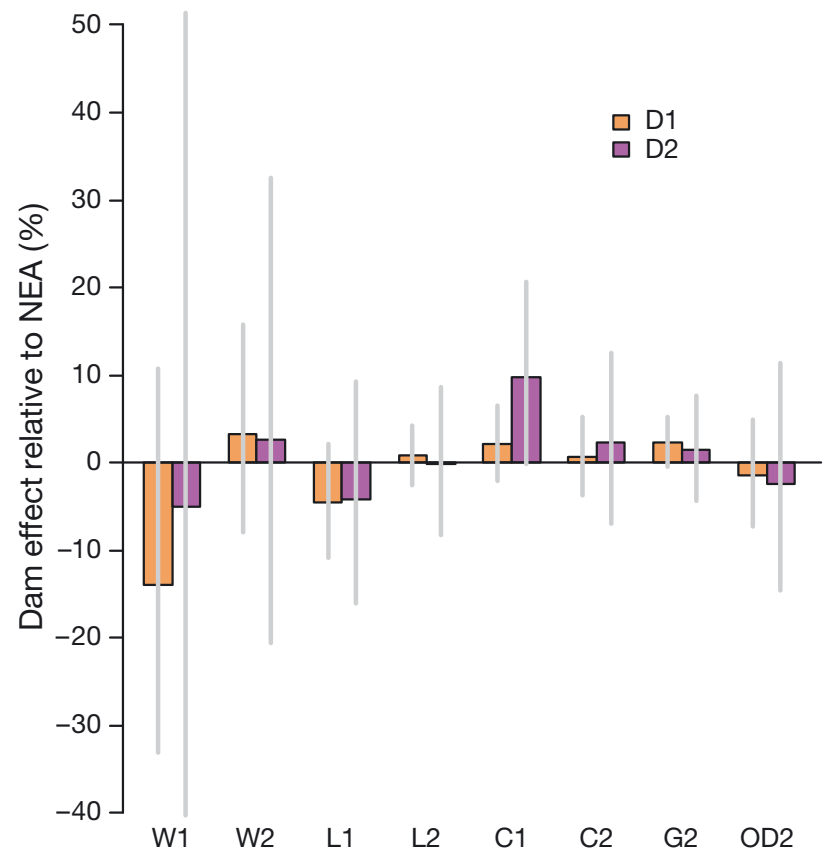

Fig. 3. Modeled effect of cod dam group on different measures taken at end of Phases I and II of Expt A. The dam effects for broodstock groups D1 and D2 are given as a percentage relative to the wild Northeast Arctic (NEA) group. Error bars show $95 \%$ confidence limits. See Table 2 for further description of modeling results. W: weight; L: length; C: condition factor; G: specific growth rate; OD: oocyte diameter; 1, 2: Phase I,II 


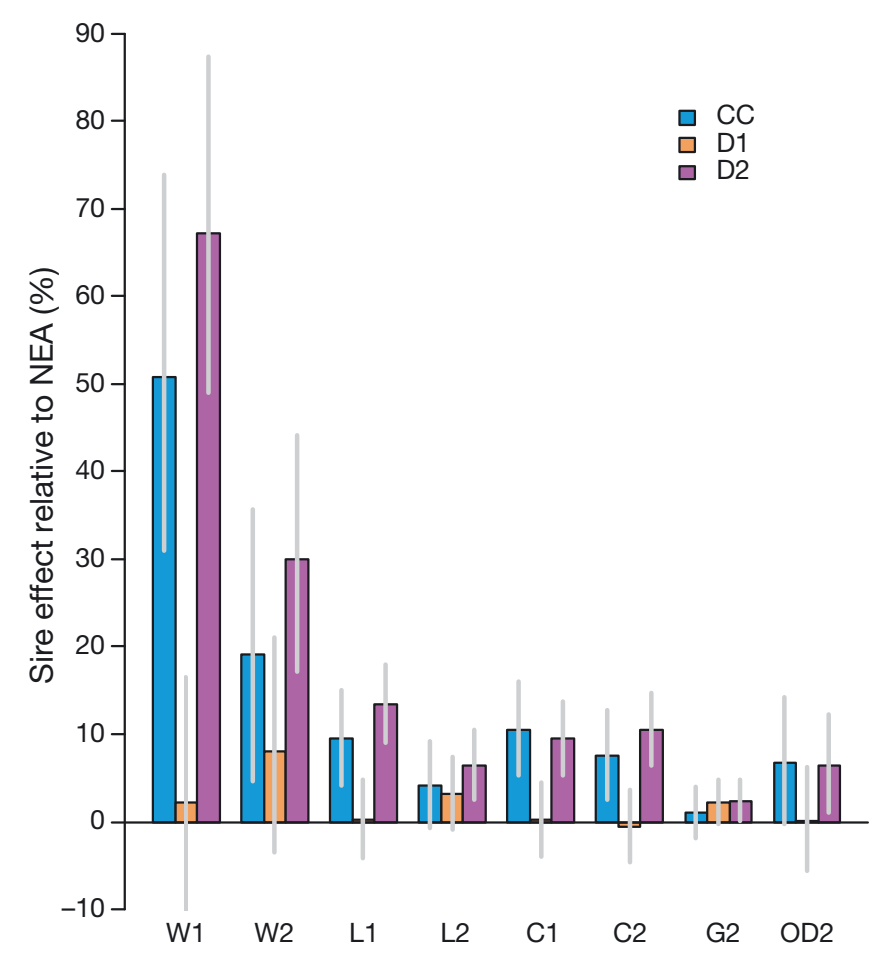

Fig. 4. Modeled effect of cod sire group on different measures taken at end of Phases I and II of Expt A. The sire effects for broodstock groups D1 and D2 and wild-caught coastal cod (CC) are given as a percentage relative to the wild Northeast Arctic (NEA) group. Error bars show $95 \%$ confidence limits. Parameter codes as in Fig. 3. See Table 2 for further description of modeling results

1841, 1659 and $1509 \mathrm{~g}$ for CC, D1 and NEA, respectively. The estimated heritability for weight was 0.32 at the end of Phase I and 0.26 at the end of Phase II.

The observed patterns for fish length at the end of Phase I were similar to the patterns described above for weight. At the end of Phase II, the differences were again reduced and only significant for D2 (Table 2, Fig. 4). CC and D2 also had significantly higher condition at both points of measurement (Table 2, Fig. 4).

Oocyte diameter (February 2014), which is regarded as a proxy for spawning time, was the largest for CC and D2, and similar for NEA and D1 (Table 2, Fig. 4). This indicates a later time of spawning for the latter groups. Sex did not influence size or condition factor at the end of Phase I, but by the end of Phase II, significant differences had developed between the sexes in length, weight, condition factor and growth. All of these measurements were significantly lower for males than females (Table 2). GSI and HSI values were only available after the fish were terminated in January 2015. Due to the temperature-induced mortality in the summer of 2014 , only $\sim 45 \%$ of the individuals were present in the terminal sample in January 2015, and the results are therefore not presented in Table 3. However, neither HSI nor GSI of the surviving fish showed significant differences between dams or sires ( $p>0.05)$.

As mentioned above, between February 2014 and January 2015, more than half of the fish died. This mortality was not random but varied significantly between the progeny of individual dams and sires (generalized linear mixed model with logit link: $p<0.001$ for both dams and sires as random effects). However, there were no clear differences among sire groups ( $p=0.1137)$ or dam groups $(\mathrm{p}=0.0543)$, despite some tendency for the D2 dam group to have lower survival compared to the wild NEA dam group. However, males suffered from much higher mortality (59\%) than females ( $47 \%$; sex as fixed effect: odds ratio 2.3 , $\mathrm{p}<0.001$ ). Moreover, large individuals suffered from higher mortality than small ones, with 1 SD positive weight anomaly (417 g) in February 2014 resulting in an increase in the odds of dying by 1.65 (weight as a variate: $\mathrm{p}<0.001)$. Table $\mathrm{S} 1$ in the Supplement at www.int-res.com/articles/suppl/q010p187_supp.pdf gives average values of length, weight and condition at termination for each of the families.

\section{Expt B (growth in mesocosms then tanks, 0-18 mo post-hatch)}

Expt B did not include CC in the design, and dams were treated as individuals in the model, as opposed to dam-group in the model used for Expt A. In Expt B, D2 displayed a significantly higher weight at the end of Phase I as compared to the NEA reference group, and this difference persisted to the end of Phase II (Table 3, Fig. 5). Average weight per sire group at the end of Expt B was $829 \mathrm{~g}$ for D2 compared to 665 and $589 \mathrm{~g}$ for D1 and NEA, respectively. Thus, its growth, relative to the other strains, was similar between both experiments using different parental fish. Similar relative differences, but lesser in magnitude, were also found in length and condition for the end of both Phases I and II, with D2 having the highest modeled values (Table 3, Fig. 5).

Despite the fact that D1 displayed the lowest estimated weight at the end of Phase I (not significantly different from NEA) they seemed to catch up with D2, showing a high growth rate similar to the D2 group, both growing significantly faster than NEA (Table 3, Fig. 5). According to the model, the estimated average weight at the end of Phase II was 46 and 9\% higher for D2 and D1, respectively, relative to NEA sires. 
Table 3. Results of the statistical analyses with mixed models in Expt B. For fixed effects, 'effect' indicates the significance of individual factor levels relative to the wild Northeast Arctic cod (NEA, for dam and sire group) or females (for sex); symbols are as in Table 1. The order of individual dams is 'D1-1, D1-2, D1-3, D1-4' and types of sire is 'D1, D2' (see Table 1 for descriptions of groups). For random effects, 'effect' is the corresponding standard deviation; residual standard deviation is shown for reference. Growth is measured as specific growth rate, with $\log ($ start weight) as an additional explanatory variable to account for growth declining with initial size (p < 0.0001$)$. Hepatosomatic index (HSI) shows strong positive allometry and is modeled as gutted-weight dependent liver weight (see 'Materials and methods'); the estimated allometric exponent is 2.04 (SE 0.02)

\begin{tabular}{|c|c|c|c|c|c|c|c|c|c|c|c|c|}
\hline \multicolumn{3}{|c|}{ End of phase I / start of phase II } & \multicolumn{2}{|c|}{ Weight } & \multicolumn{2}{|c|}{ Length } & \multicolumn{2}{|c|}{ Condition } & & & & \\
\hline & Term & df & $\mathrm{p}$ & Effect & $\mathrm{p}$ & Effect & $\mathrm{p}$ & Effect & & & & \\
\hline \multirow{3}{*}{$\begin{array}{l}\text { Fixed } \\
\text { effects }\end{array}$} & Sex & 1 & 0.3615 & 0 & 0.2453 & 0 & 0.2741 & 0 & & & & \\
\hline & Dam & 4 & 0.0054 & $000-$ & 0.0254 & $000(-)$ & 0.7314 & 0000 & & & & \\
\hline & Sire group & 2 & $<0.0001$ & $0+$ & 0.0019 & $0+$ & $<0.0001$ & $0+$ & & & & \\
\hline \multirow{3}{*}{$\begin{array}{c}\text { Random } \\
\text { effects } \\
\text { Residual }\end{array}$} & Sire & $\geq 1$ & $<0.0001$ & 0.122 & $<0.0001$ & 0.044 & $<0.0001$ & 0.042 & & & & \\
\hline & Tank & $\geq 1$ & $<0.0001$ & 0.139 & $<0.0001$ & 0.040 & 1.0000 & 0.000 & & & & \\
\hline & & $\leq 1663$ & & 0.283 & & 0.084 & & 0.073 & & & & \\
\hline \multicolumn{3}{|c|}{ End of phase II } & \multicolumn{2}{|c|}{ Weight } & \multicolumn{2}{|c|}{ Length } & \multicolumn{2}{|c|}{ Condition } & \multicolumn{2}{|c|}{ Growth } & \multicolumn{2}{|c|}{ HSI } \\
\hline & Term & $\mathrm{df}$ & $\mathrm{p}$ & Effect & $\mathrm{p}$ & Effect & $\mathrm{p}$ & Effect & $\mathrm{p}$ & Effect & $\mathrm{p}$ & Effect \\
\hline \multirow{3}{*}{$\begin{array}{l}\text { Fixed } \\
\text { effects }\end{array}$} & Sex & 1 & 0.9642 & 0 & 0.5479 & 0 & 0.1438 & 0 & 0.7165 & 0 & 0.0093 & + \\
\hline & Dam & 4 & $<0.0001$ & ++00 & 0.0049 & $(+) 000$ & 0.2805 & 0000 & $<0.0001$ & ++00 & 0.0873 & $000(+)$ \\
\hline & Sire group & 2 & $<0.0001$ & $0+$ & 0.0001 & $0+$ & 0.0388 & $0(+)$ & $<0.0001$ & ++ & 0.0005 & $0-$ \\
\hline \multirow{3}{*}{$\begin{array}{l}\text { Random } \\
\text { effects } \\
\text { Residual }\end{array}$} & Sire & $\geq 1$ & 1.0000 & 0.057 & $<0.0001$ & 0.030 & $<0.0001$ & 0.065 & 1.0000 & 0.018 & $<0.0001$ & 0.115 \\
\hline & History & $\geq 1$ & $<0.0001$ & 0.069 & $<0.0001$ & 0.020 & $<0.0001$ & 0.020 & $<0.0001$ & 0.029 & $<0.0001$ & 0.047 \\
\hline & & $\leq 1666$ & & 0.340 & & 0.089 & & 0.105 & & 0.168 & & 0.272 \\
\hline
\end{tabular}

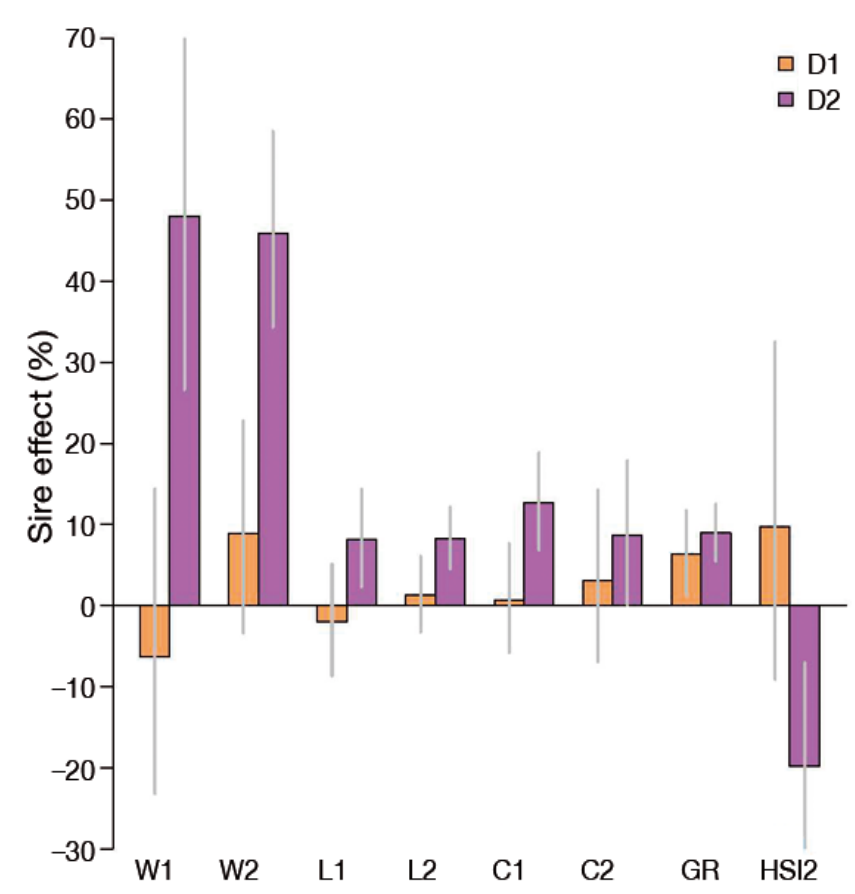

Fig. 5. Modeled effect of cod sire group on different measures taken at the end of Phases I and II in Expt B. The sire effects for broodstock groups D1 and D2 are given as a percentage relative to the wild Northeast Arctic (NEA) group. Error bars show $95 \%$ confidence limits. HSI: hepatosomatic index of Phase II; other parameter codes as in Fig. 3. See Table 3 for further description of modeling results
No significant difference between males and females developed during Expt B, except for HSI, which was higher for the males at the end of the experiment (Table 3). Furthermore, HSI was significantly lower for D2 compared to NEA, whereas no difference was found for D1. GSI was below $1 \%$ for all groups, suggesting that maturation had not started yet. Table S2 in the Supplement gives average values of length, weight and condition at termination for each of the families.

\section{DISCUSSION}

This is the first study to compare growth of partly domesticated Atlantic cod and their wild counterparts. Using a common-garden experimental design, whereby all families were communally reared in 2 parallel experiments, we observed significantly higher growth in the offspring from 1 of the domesticated groups (D2), compared to offspring from wild NEA cod. However, the second domesticated group (D1) did not display any significant increase in growth compared to either wild population. We therefore conclude that by the second generation, Atlantic cod breeding programs initiated in Norway have been partly successful in increasing growth rate through selection. Thus, our data confirm that selection for 
this trait can significantly increase performance of the species in the domestic environment, which is consistent with earlier studies demonstrating significant heritability for this trait.

Maternal effects on juvenile growth and survival are well documented in fish, including cod in rearing systems (e.g. Blom et al. 1994, Clemmesen et al. 2003). However, most of the results of our study are based on sire effects (i.e. additive genetic variation). This was due to the unbalanced design between sexes, with relatively few dams used. Based upon these results, differences in weight between the experimental groups at the end of Phase I were consistent, with D2 showing the highest weight. Furthermore, this difference was consistent between both experiments which involved different broodfish. Therefore, our main findings are robust and representative for the strains tested. Surprisingly, however, the other domesticated group studied (D1) did not show any clearly increased growth compared to either wild group. Furthermore, the local coastal cod group (CC, Expt A only) was also significantly heavier than both the NEA and D1 groups at this time. Based on the modeled sire effect, 1 of the 2 domesticated groups (D2) was 30 and $46 \%$ heavier than the wild NEA group in Expts A and B, respectively (in terms of actual weights, 1934 and $829 \mathrm{~g}$ for D2 as opposed to 1509 and $589 \mathrm{~g}$ for NEA) at the end of Phase II.

There are 2 possible major reasons for the difference in growth between the 2 domesticated groups during Phase I of the experiment: (1) they have different genetic backgrounds and therefore display inherently different growth rates, or (2) they are in different phases of the domestication process. The slower-growing D1 strain is founded on NEA cod, while the faster-growing D2 strain is founded on a mixture of NEA and CC. Even though we do not know the exact genetic composition of the D2 strain, it is possible that the $\mathrm{CC}$ contribution to the strain has been beneficial for growth under the current rearing conditions. This was also reflected in the fact that the local CC group grew nearly as fast as the domesticated D2 group during phase I, and faster than NEA and D1. NEA cod typically live in colder temperatures compared to CC from the southern part of Norway. Several experiments have indicated a higher growth of CC than NEA cod when reared under conditions similar to those used in the present experiment. For example, van der Meeren et al. (1994) reported higher growth of CC compared to NEA cod during the larval stage reared in mesocosms at a latitude similar to our study. These same groups were followed further until sexual maturation by Svåsand et al. (1996). They found a tendency of higher specific weight increase in the CC group, mainly due to differences in growth during the warmer summer months. However, it should be mentioned that their CC group had been kept in captivity for a few generations. In a series of laboratory experiments, Otterlei et al. (1999) found both higher growth and condition factor in CC than NEA cod during the larval stage at temperatures from 4 to $14^{\circ} \mathrm{C}$. In contrast, Kolstad et al. (2006b) did not find any differences in fish size between family groups of CC or NEA cod reared at 3 different locations along the Norwegian coast. They therefore concluded that separate breeding programs based on these 2 groups were not necessary. Furthermore, Bangera et al. (2015) reported a low genotype $\times$ environment interaction when they tested cod from the same breeding program as in the current experiment in southern and northern Norway.

In the present study, oocyte diameters of $\mathrm{CC}$ and D2 were similar and larger than those of NEA and D1. Oocyte development has been used as a proxy for spawning time along a north-south gradient (Otterå et al. 2012), and the present findings are in accordance with earlier spawning for the southern component (wild CC and domesticated cod mainly based on CC, i.e. group D2) as compared to the more northern wild NEA and domesticated D1. As mentioned above, D1 is also based on NEA cod.

The fact that the wild NEA group displayed similar growth to the domesticated NEA-based group (D1) was unexpected, and does not suggest clear growth improvement for this specific breeding program thus far. The parents of D1 and D2 were both F2 generation in their respective breeding programs. Experience from Atlantic salmon breeding suggests an increase in growth rate of $10-15 \%$ per generation during the early phase of domestication (Gjedrem 2000,2010 ), and after $\sim 10$ generations, domesticated salmon typically out-grow wild salmon 2-5 times under identical tank-rearing conditions (reviewed by Glover et al. 2017). Compared to salmon farming, Atlantic cod farming is still in its infancy, and progress in rearing protocols and other non-genetic changes from one generation to the next may have confounded the selection process and thereby made the breeding programs less effective than one should expect given the relatively high heritability estimates for this species for growth (Gjerde et al. 2004, Garber et al. 2010, Tosh et al. 2010, Bangera et al. 2011, Kristjánsson \& Arnason 2016). Furthermore, both breeding programs that provided selected broodstock for the 
current study are based on an intensive larval rearing protocol. Here, we used a semi-natural rearing environment during the larval and early juvenile period which may have influenced the results to some extent. Nevertheless, the 30-46\% larger weight at termination of D2 compared to the NEA group is a promising result in terms of breeding progress, particularly when it is considered that these results were obtained for sire groups, and that the pure strain effects should theoretically be twice as large when the additive effect from the dam is included.

The major part of the growth differences between the groups developed during Phase I of both experiments. In the first 2 mo of Phase I, juveniles relied entirely upon natural food, and it is likely that the growth differences to some degree could be caused by a more competitive environment during that period, with the larger individuals gaining the best access to food. Whether or not this differentially influenced the relative growth of the partly domesticated and wild strains in this study is not easy to tell; however, it is still noteworthy that D2 out-grew all groups despite the fact that both D1 and D2 breeding programs are based upon intensive rearing protocols.

Although not quantified, it is likely that cannibalism was an important cause of the mortality during Phase I of both experiments, but not during Phase II of either Expt A or Expt B, where mortality was very low. It is expected that cannibalism is a main cause for size-selective mortality in cod juveniles (Folkvord 1991), and this mainly occurs during the late larval/ early juvenile period (Folkvord \& Otterå 1993). This would obviously influence competition, including risk of predation, during that period. If such mechanisms were present in our experiment, this would have increased growth differences between groups in the potentially 'food limiting' period (Phase I) and decreased such differences in the 'ad lib' period (Phase II). Finally, purely allometric factors will tend to reduce growth differences when these are given as size-specific rates (like specific growth rate), due to the general decline in such rates as a fish becomes larger (Jobling 1983).

Genetic interactions between farmed escapees and wild conspecifics represents one of the primary challenges to environmental sustainability of aquaculture (Bekkevold et al. 2006, Taranger et al. 2015, Glover et al. 2017). Although the cod farming industry is currently experiencing low productivity, the potential for genetic interactions between escapees and wild conspecifics is high, given that cod have the ability to escape into the wild via spawning within cages (Jørstad et al. 2008), as well as escape into the wild itself (Uglem et al. 2008, Jensen et al. 2010). In Norway where this has been studied, interactions between farmed escaped cod and wild populations have already been reported (Glover et al. 2010, 2011, Varne et al. 2015). While the present study did not investigate potential fitness differences between partly domesticated and wild cod, we did investigate growth differences as a proxy for domestication status. Consequently, the present study, representing the first experimental estimation of the effect of domestication in Atlantic cod, provides important background information for the possible interactions between farmed (domesticated) and wild cod populations. Following up this first study with investigations of other important domestication-related traits, such as predator avoidance and survival in a natural environment, is encouraged, especially using cod strains that are now possibly in a further stage of domestication. Furthermore, it is possible to produce triploid (sterile) cod at a commercial scale (Otterå et al. 2016), and this or alternative sterilization strategies could be implemented in order to mitigate potential genetic interactions between farmed and wild cod, including the challenge of within-farm spawning.

Acknowledgements. We acknowledge the technical assistance of IMR staff at Parisvatnet for broodstock rearing and help during Phase I of the experiment. We also acknowledge the technical assistance of the IMR staff at Austevoll for help during Phase II, and thank the lab technicians at IMR, Bergen, for genotyping the broodstock and offspring and measuring oocyte diameters. Thanks to Atle Mortensen of Nofima Tromsø for donation of broodstock material. The experiment was financed by the Norwegian Research Council Project INTERACT.

\section{LITERATURE CITED}

Árnason T, Björnsson B (2012) Spawning-related mortality in captive Atlantic cod (Gadus morhua L.). Aquacult Res 43:292-296

Bangera R, Ødegard J, Praebel AK, Mortensen A, Nielsen HM (2011) Genetic correlations between growth rate and resistance to vibriosis and viral nervous necrosis in Atlantic cod (Gadus morhua L.). Aquaculture 317:67-73

*Bangera R, Drangsholt TMK, Nielsen HM, Sae-Lim P and others (2015) Genotype by environment interaction for growth in Atlantic cod (Gadus morhua L.) in four farms of Norway. J Mar Sci Eng 3:412-427

Bates D, Maechler M, Bolker B, Walker S (2014) lme4: Linear mixed-effects models using Eigen and S4. R package version 1.0-4. https://github.com/lme4/lme4/

Bekkevold D, Hansen MM, Nielsen EE (2006) Genetic impact of gadoid culture on wild fish populations: predictions, lessons from salmonids, and possibilities for minimizing adverse effects. ICES J Mar Sci 63:198-208 
Bergstad OA, Jørgensen T, Dragesund O (1987) Life history and ecology of the gadoid resources of the Barents Sea. Fish Res 5:119-161

Blom G, Otterå H, Svåsand T, Kristiansen TS, Serigstad B (1991) The relationship between feeding conditions and production of cod fry (Gadus morhua L.) in a semienclosed marine ecosystem in western Norway, illustrated by use of a consumption model. ICES Mar Sci Symp 192:176-189

Blom G, Svåsand T, Jørstad KE, Otterå H, Paulsen OI, Holm JC (1994) Comparative survival and growth of two strains of Atlantic cod (Gadus morhua) through the early life stages in a marine pond. Can J Fish Aquat Sci 51:1012-1023

Brown JA, Minkoff G, Puvanendran V (2003) Larviculture of Atlantic cod (Gadus morhua): progress, protocols and problems. Aquaculture 227:357-372

* Clemmesen C, Bühler V, Carvalho G, Case R and others (2003) Variability in condition and growth of Atlantic cod larvae and juveniles reared in mesocosms: environmental and maternal effects. J Fish Biol 62:706-723

* Duarte CM, Marbá N, Holmer M (2007) Rapid domestication of marine species. Science 316:382-383

Folkvord A (1991) Growth, survival and cannibalism of cod juveniles (Gadus morhua): effects of feed type, starvation and fish size. Aquaculture 97:41-59

Folkvord A, Otterå H (1993) Effects of initial size distribution, day length, and feeding frequency on growth, survival, and cannibalism in juvenile Atlantic cod (Gadus morhua L.). Aquaculture 114:243-260

Garber AF, Tosh JJ, Fordham SE, Hubert S and others (2010) Survival and growth traits at harvest of communally reared families of Atlantic cod (Gadus morhua). Aquaculture 307:12-19

Gjedrem T (2000) Genetic improvement of cold-water fish species. Aquacult Res 31:25-33

Gjedrem T (2010) The first family-based breeding program in aquaculture. Rev Aquacult 2:2-15

Gjedrem T, Gjøen HM, Gjerde B (1991) Genetic origin of Norwegian farmed Atlantic salmon. Aquaculture 98:41-50

* Gjerde B, Terjesen BF, Barr Y, Lein I, Thorland I (2004) Genetic variation for juvenile growth and survival in Atlantic cod (Gadus morhua). Aquaculture 236:167-177

Glover KA, Dahle G, Westgaard JI, Johansen T, Knutsen H, Jørstad KE (2010) Genetic diversity within and among strains of farmed Atlantic cod (Gadus morhua): a proofof-concept study for the identification of escapees. Anim Genet 41:515-522

Glover KA, Dahle G, Jørstad KE (2011) Genetic identification of farmed and wild Atlantic cod, Gadus morhua, in coastal Norway. ICES J Mar Sci 68:901-910

Glover KA, Solberg MF, McGinnity P, Hindar K and others (2017) Half a century of genetic interaction between farmed and wild Atlantic salmon: status of knowledge and unanswered questions. Fish Fish 18:890-927

Hutchings JA, Fraser DJ (2008) The nature of fisheries- and farming-induced evolution. Mol Ecol 17:294-313

Jensen Ø, Dempster T, Thorstad EB, Uglem I, Fredheim A (2010) Escapes of fishes from Norwegian sea-cage aquaculture: causes, consequences and prevention. Aquacult Environ Interact 1:71-83

Jobling M (1983) Growth studies with fish-overcoming the problems of size variation. J Fish Biol 22:153-157

Jørstad K, van der Meeren T, Paulsen OI, Thomsen T, Thorsen A, Svåsand T (2008) Escapes of eggs from farmed cod spawning in net pens: recruitment to wild stocks. Rev Fish Sci 16:285-295

* Jørstad KE, Otterå H, van der Meeren T, Dahle G, Paulsen OI, Bakke G, Svåsand T (2014) Genetic marking of farmed Atlantic cod (Gadus morhua L.) and detection of escapes from a commercial cod farm. ICES J Mar Sci 71:574-584

*Karlsen Ø, Norberg B, Kjesbu OS, Taranger GL (2006) Effects of photoperiod and exercise on growth, liver size, and age at puberty in farmed Atlantic cod (Gadus morhua L.). ICES J Mar Sci 63:355-364

Kjesbu OS (1994) Time of start of spawning in Atlantic cod (Gadus morhua) females in relation to vitellogenic oocyte diameter, temperature, fish length and condition. J Fish Biol 45:719-735

*Kjesbu OS, Righton D, Krüger-Johnsen M, Thorsen A, Michalsen K, Fonn M, Witthames PR (2010) Thermal dynamics of ovarian maturation in Atlantic cod (Gadus morhua). Can J Fish Aquat Sci 67:605-625

Knutsen H, Jorde PE, Andre C, Stenseth NC (2003) Finescaled geographical population structuring in a highly mobile marine species: the Atlantic cod. Mol Ecol 12: 385-394

Kolstad K, Thorland I, Refstie T, Gjerde B (2006a) Genetic variation and genotype by location interaction in body weight, spinal deformity and sexual maturity in Atlantic cod (Gadus morhua) reared at different locations off Norway. Aquaculture 259:66-73

Kolstad K, Thorland I, Refstie T, Gjerde B (2006b) Body weight, sexual maturity, and spinal deformity in strains and families of Atlantic cod (Gadus morhua) at two years of age at different locations along the Norwegian coast. ICES J Mar Sci 63:246-252

Kristjánsson T, Arnason T (2016) Heritability of economically important traits in the Atlantic cod Gadus morhua L. Aquacult Res 47:349-356

* Otterå H, Agnalt AL, Thorsen A, Kjesbu OS, Dahle G, Jørstad $K$ (2012) Is spawning time of marine fish imprinted in the genes? A two-generation experiment on local Atlantic cod (Gadus morhua L.) populations from different geographical regions. ICES J Mar Sci 69:1722-1728

* Otterå H, Thorsen A, Karlsen Ø, Fjelldal PG, Morton HC, Taranger GL (2016) Performance of triploid Atlantic cod (Gadus morhua L.) in commercial aquaculture. Aquaculture 464:699-709

\% Otterlei E, Nyhammer G, Folkvord A, Stefansson SO (1999) Temperature- and size-dependent growth of larval and early juvenile Atlantic cod (Gadus morhua): a comparative study of Norwegian coastal cod and northeast Arctic cod. Can J Fish Aquat Sci 56:2099-2111

* Serra-Llinares RM, Nilsen R, Uglem I, Arechavala-Lopez P, Bjørn PA, Noble C (2013) Post-escape dispersal of juvenile Atlantic cod Gadus morhua from Norwegian fish farms and their potential for recapture. Aquacult Environ Interact 3:107-116

* Svåsand T, Jørstad KE, Otterå H, Kjesbu OS (1996) Differences in growth performance between Arcto-Norwegian and Norwegian coastal cod reared under identical conditions. J Fish Biol 49:108-119

Svåsand $\mathrm{T}$, Otterå $\mathrm{H}$, Taranger GL (2004) Atlantic cod (Gadus morhua). In: Moksness E, Kjørsvik E, Olsen Y (eds) Culture of cold-water marine fish. Blackwell Scientific Publications Ltd, Oxford, p 432-444

* Taggart JB (2007) FAP: an exclusion-based parental assignment program with enhanced predictive functions. Mol Ecol Notes 7:412-415 
Taranger GL, Karlsen Ø, Bannister RJ, Glover KA and others (2015) Risk assessment of the environmental impact of Norwegian Atlantic salmon farming. ICES J Mar Sci 72:997-1021

Teletchea F, Fontaine P (2014) Levels of domestication in fish: implications for the sustainable future of aquaculture. Fish Fish 15:181-195

Thorsen A, Kjesbu OS (2001) A rapid method for estimation of oocyte size and potential fecundity in Atlantic cod using a computer-aided particle analysis system. J Sea Res 46:295-308

Tosh JJ, Garber AF, Trippel EA, Robinson JAB (2010) Genetic, maternal, and environmental variance components for body weight and length of Atlantic cod at two points in life. J Anim Sci 88:3513-3521

Uglem I, Bjørn PA, Dale T, Kerwath S and others (2008) Movements and spatiotemporal distribution of escaped farmed and local wild Atlantic cod (Gadus morhua L.). Aquacult Res 39:158-170

van der Meeren T, Ivannikov VP (2006) Seasonal shift in

Editorial responsibility: Megan La Peyre,

Baton Rouge, Louisiana, USA spawning of Atlantic cod (Gadus morhua L.) by photoperiod manipulation: egg quality in relation to temperature and intensive larval rearing. Aquacult Res 37:898-913

van der Meeren T, Jørstad K, Solemdal P, Kjesbu O (1994) Growth and survival of cod larvae (Gadus morhua L.): comparative enclosure studies of Northeast Arctic cod and coastal cod from western Norway. ICES Mar Sci Symp 198:633-645

* Varne R, Kunz KL, Johansen T, Westgaard JI, Uglem I, Mork $\mathrm{J}$ (2015) Farmed cod escapees and net-pen spawning left no clear genetic footprint in the local wild cod population. Aquacult Environ Interact 7:253-266

Wringe BF, Fleming IA, Purchase CF (2015) Rapid morphological divergence of cultured cod of the northwest Atlantic from their source population. Aquacult Environ Interact 7:167-177

* Zimmermann EW, Purchase CF, Fleming IA, Brattey J (2013) Dispersal of wild and escapee farmed Atlantic cod (Gadus morhua) in Newfoundland. Can J Fish Aquat Sci 70:747-755

Submitted: June 29, 2017; Accepted: February 12, 2018 Proofs received from author(s): April 4, 2018 